\title{
Knowledge, accessibility, and utilization of insecticide treated nets among pregnant women in a selected hospital in South-Eastern Nigeria
}

\author{
Chiamaka J. Okafor ${ }^{1}$, Ngozi P. Ogbonnaya ${ }^{1}$
}

\begin{abstract}
INTRODUCTION Prevention of malaria in pregnancy (MIP) with the use of insecticide treated nets (ITNs) is no doubt one of the major interventions aimed at reducing maternal and infant morbidity and mortality rates. This study aimed to determine the knowledge, accessibility and utilization of ITNs during pregnancy.

METHODS This is a quantitative survey conducted in 2014 among pregnant women attending ANC in Redeemer Hospital and Maternity, Abakpa-Nike, Enugu State, SouthEastern Nigeria. One hundred and forty participants were selected using convenience sampling and information elicited using a self-developed questionnaire. Data were analysed using SPSS (version 9) and results presented in frequency tables.

RESULTS Among the respondents, $90.7 \%$ knew of the effectiveness of ITNs in the prevention of MIP. Results also showed that most of the women (69.3\%) own at least one ITN, and their major source was from the free house-to-house distribution by the government. Also, $62.9 \%$ revealed that the ITNs were readily available. Out of the 97 women that owned at least one ITN, the majority (69.1\%) claimed to have started using ITNs even before pregnancy with 70\% claiming to sleep under the ITNs always. Nevertheless, only $69.1 \%$ used an ITN correctly.

CONCLUSIONS There is high knowledge of ITNs and their effectiveness in prevention of MIP among pregnant women in Enugu South-Eastern Nigeria. However, there is a need for measures to increase awareness on their correct usage, and also to correct misconceptions and wrong beliefs associated with ITNs in order to enhance their utilization.
\end{abstract}

\section{AFFILIATION \\ 1 Department of Nursing Sciences, University of Nigeria, Nsukka, Nigeria}

\section{GORRESPONDENGE TO}

Chiamaka J. Okafor. Department of Nursing Sciences, University of Nigeria, Nsukka - Onitsha Rd, Nsukka, Nigeria.

E-mail: chiamaka.okafor@unn. edu.ng ORCID ID: https://orcid. org/0000-0001-8915-2622

\section{KEYWORDS}

pregnancy, malaria, mosquito, insecticide treated nets

Received: 5 December 2019

Revised: 2 July 2020

Accepted: 17 November 2020

\section{INTRODUCTION}

Malaria has been a world health burden and a major public health problem in tropical and subtropical regions of the world. It affects an estimated 350 to 500 million people annually and accounts for 1 to 3 million deaths per year worldwide ${ }^{1-3}$. In its periodic health report, the World Health Organization (WHO) stated that more than 90\% of the world's malaria cases (an estimated 0.8 million annually) are unreported ${ }^{4}$. In African countries with stable malaria transmission, infection during pregnancy is estimated to cause as many as 10000 maternal deaths and 200000 neonatal deaths per year. It is also said to be responsible for $8-14 \%$ of all low birthweight babies and $3-8 \%$ of all infant deaths, and over 30 million pregnancies threatened throughout Africa each year ${ }^{5-7}$. In 2007, there were an estimated 219 million cases of malaria in 87 countries, while the number of deaths stood at 0.435 million $^{8}$.

Malaria infection during pregnancy is a significant public health problem with substantial risks for the pregnant woman, her foetus, and the newborn child. Pregnant women have attacks of malaria more often and more severely than non-pregnant women from the same area, and are more likely to die from malaria. This is because pregnancy reduces women's ability to fight malaria, especially during a woman's first pregnancy ${ }^{9}$. About 19-24 million women are at risk of malaria during pregnancy ${ }^{10}$. Malaria-associated maternal illness and low birthweight are mostly the result of Plasmodium falciparum infection and occurs predominantly in Africa ${ }^{11}$. Malaria in pregnancy also contributes to significant peri-natal morbidity and mortality. Malaria infection is known to cause higher rates of miscarriage, intrauterine demise, premature delivery, low birthweight neonates, and neonatal death ${ }^{12}$.

Prevention of malaria during pregnancy with the use of ITNs is no doubt one of the major interventions aimed at reducing maternal and infant morbidity and mortality 
rates and thus achieving the 4th, 5th and 6th Millennium Development Goals (MDGs). It has remained a cost effective and highly efficient tool in global and national malaria control policies $^{13,14}$ and it is estimated to be twice as effective as the untreated nets5. The 2008 Nigeria Demographic and Health Survey (NDHS) results indicate that $17 \%$ of households in Nigeria own a mosquito net (treated or untreated), and $8 \%$ of households own more than one mosquito net and $16 \%$ of households own at least one net that has never been treated. The average number of ITNs per household was less than one, which could be attributed to a weak supply and distribution mechanism ${ }^{5}$.

In recent years, the distribution of ITNs has been inadequate, with only a few local government areas targeted in various states. This has made it impossible to attain saturation in any one area ${ }^{5}$. The approach since 2009 has been to start afresh a coordinated strategy to deliver 2 nets to every household across the country through a series of stand-alone campaigns to achieve universal coverage. In 2010, the world-bank booster-supported states (Kano, Jigawa, Bauchi, Gombe, Anambra, Akwaibom, and Rivers) conducted net campaigns, and health workers distributed free nets to households. The aim was to promote net-use in households, especially among pregnant women and children below 5 years of age ${ }^{5}$. According to the Federal Ministry of Health, 57.7 million nets were distributed between 20092013 across Nigeria, representing 90.2\% of the national overall coverage target ${ }^{15}$. This coverage represented a huge success in the collective efforts to scale up the intervention.

Again, anecdotal reports from both tertiary health facilities and primary healthcare centres in Enugu, SouthEastern Nigeria, show that the use of ITNs is somewhat limited. Our literature review and observations also show that documentations on the knowledge, accessibility, and use of ITNs by this vulnerable group are also limited. It is not known whether the poor usage observed is due to a lack of knowledge about ITNs and their importance, or because access to ITNs is poor, or because there are other constraining factors. It is also not known whether usage and opinions about access to ITNs have improved over time. These issues motivated this study among antenatal care attendees of Redeemer Maternity, Abakpa Nike, Enugu, South-Eastern Nigeria to determine the knowledge, accessibility and utilisation of insecticide treated nets during pregnancy.

\section{METHODS}

The current quantitative study was undertaken at Redeemer Hospital and Maternity, Abakpa Nike, Enugu State, SouthEastern Nigeria. The study population consisted of all the pregnant women who attend the antenatal care clinic within 6 weeks of the study. One hundred and forty pregnant women were recruited and included in the study. The inclusion criteria included: 1) must be a pregnant woman; 2) must be attending ANC at Redeemer Hospital and Maternity, Abakpa Nike; and 3) must be willing to participate in the study. On the other hand, the exclusion criterion entailed those who refused to sign the consent form.
The proposal for this study was reviewed and approved by the hospital ethics board. Participants were informed about the purpose and details of the study and written consent was obtained from them prior to the commencement of the study. A self-developed questionnaire was used for the study. The questionnaire was constructed based on the research objective. The questionnaire had two sections. Section A comprised the sociodemographic data, while Section B comprised questions or items set to generate data for the research, based on the research questions. Most of the questions were designed in close ended format, which gives the respondent the opportunity to choose from the options provided, while others were in open ended format where the respondents were expected to write their own opinions.

The reliability of the instrument was tested by carrying out a pilot survey in which 25 copies of the questionnaire were administered to 25 pregnant women at Annunciation Specialist Hospital, Emene, Enugu East LGA. Data generated were tested for internal consistency (the degree to which all of the items measure a common characteristic). A reliability coefficient of 0.89 was obtained using Cronbach's alpha. Thus, the instrument was considered reliable. Data were analysed using SPSS (version 9) and are presented in frequency tables.

\section{RESULTS}

The demographic profile of participants is presented in Table 1. All the respondents had knowledge of ITNs and $90.7 \%$ knew of their effectiveness in the prevention of malaria in pregnancy. The majority (45\%) obtained the information by attending antenatal clinics; only a few (4.3\%) were informed by their family (Table 2). Results also show that most of the women (69.3\%) own at least one ITN, and their major source was from the free house-to-house distribution by the government. Also, 62.9\% revealed that the ITNs were readily available (Table 3 ).

\section{Utilisation of ITNs by pregnant women}

Out of the 97 women that owned at least one ITN, the majority (69.1\%) claimed to have started using ITNs even before pregnancy with $70 \%$ claiming to sleep under the ITNs always. Regarding the correct use of an ITN, 69.1\% stated that they used it correctly, hanging it over the bed and tucking it under the mattress to prevent contact with the body while sleeping under it. Others stated that they hung it over their doors and windows to prevent mosquitoes

\section{Table 1. Sociodemographic characteristics of respondents $(N=140)$}

\begin{tabular}{|l|l|r|r|}
\hline Characteristics & Categories & $\boldsymbol{n}$ & $\%$ \\
\hline Age (years) & $<20$ & 9 & 6.4 \\
\hline $20-29$ & 94 & 67.1 \\
\hline $30-39$ & 37 & 26.5 \\
\hline & $\geq 40$ & - & - \\
\hline
\end{tabular}


Table 1. Continued

\begin{tabular}{|c|c|c|c|}
\hline Characteristics & Categories & $n$ & $\%$ \\
\hline \multirow{4}{*}{$\begin{array}{l}\text { Highest educational } \\
\text { level }\end{array}$} & No formal education & - & - \\
\hline & Primary & 18 & 12.9 \\
\hline & Secondary & 74 & 52.8 \\
\hline & Tertiary & 48 & 34.3 \\
\hline \multirow[t]{5}{*}{ Parity } & 1 & 47 & 33.6 \\
\hline & 2 & 53 & 37.8 \\
\hline & 3 & 20 & 14.3 \\
\hline & 4 & 12 & 8.6 \\
\hline & $\geq 5$ & 8 & 5.7 \\
\hline \multirow[t]{3}{*}{ Religion } & Christian & 140 & 100 \\
\hline & Islam & - & - \\
\hline & Traditional worshipper & - & - \\
\hline \multirow[t]{3}{*}{ Stage of pregnancy } & 1st trimester & 26 & 18.6 \\
\hline & 2nd trimester & 75 & 53.6 \\
\hline & 3rd trimester & 39 & 27.8 \\
\hline \multirow[t]{5}{*}{ Occupation } & House wife & 59 & 42.1 \\
\hline & Petty trader & 42 & 30.0 \\
\hline & Artisan & 12 & 8.6 \\
\hline & Civil servant & 19 & 3.6 \\
\hline & Student & 8 & 5.7 \\
\hline \multirow{5}{*}{$\begin{array}{l}\text { Number of malaria } \\
\text { episode occurrence(s) } \\
\text { during current } \\
\text { pregnancy }\end{array}$} & 0 & 46 & 32.9 \\
\hline & 1 & 64 & 45.7 \\
\hline & 2 & 27 & 19.3 \\
\hline & 3 & 3 & 2.1 \\
\hline & $\geq 4$ & - & - \\
\hline
\end{tabular}

Table 2. Knowledge of pregnant women regarding prevention of malaria in pregnancy using ITNs, Nigeria $(N=140)$

\begin{tabular}{l|r|r|}
\hline Items & $\boldsymbol{n}$ & $\%$ \\
\hline Do you know about ITNs & & \\
\hline Yes & - & - \\
\hline No & & \\
\hline How did you get to know about ITNs & 63 & 45.0 \\
\hline Antenatal care centres & 21 & 15.0 \\
\hline Health education campaigns & 43 & 30.7 \\
\hline Mass media (radio, TV, newspapers, etc.) & 7 & 5.0 \\
\hline Friends and colleagues & 6 & 4.3 \\
\hline $\begin{array}{l}\text { Family } \\
\text { Neighbours }\end{array}$ & - & - \\
\hline $\begin{array}{l}\text { Why do you think ITNs are important during } \\
\text { pregnancy }\end{array}$ & 127 & 90.7 \\
\hline $\begin{array}{l}\text { They reduce the contact between the pregnant } \\
\text { women and mosquitoes }\end{array}$ & \multicolumn{2}{|c|}{5.7} \\
\hline $\begin{array}{l}\text { They provide a house for the mosquitoes to stay in } \\
\text { They drive away mosquitoes from the room }\end{array}$ & 5.6 \\
\hline $\begin{array}{l}\text { It is an instruction from the antenatal clinic that } \\
\text { must be followed }\end{array}$ & - & - \\
\hline
\end{tabular}

from entering their rooms (17.5\%), while only a minority still allowed contact with the net while sleeping under it (13.4\%). Multiple issues were found that prevent correct usage of ITNs. For example, 41 (95.3\%) said they had heard that ITNs have a negative effect on the baby in the womb. Furthermore, 39 (90.7\%) said they did not know how to hang it and in any case had no facility to hang it in their room. The heat was also an issue and that the ITNs cause excessive heat and discomfort, with 32 (74.4\%) saying they cannot use them when the weather is hot. Furthermore, free distribution of ITNs was found to be a well-appreciated intervention that can increase its utilisation, as reported by $97.7 \%$ of the participants (Table 4 ).

Table 3. Accessibility to ITNs by pregnant women, Nigeria $(\mathbf{N}=97)^{*}$

\begin{tabular}{|l|c|c|}
\hline Items & $\boldsymbol{n}$ & $\%$ \\
\hline Do you own at least one ITN & & \\
\hline Yes & 97 & 69.3 \\
\hline No & 43 & 30.7 \\
\hline What is the source of your ITN & & \\
\hline Antenatal care centres & 15 & 15.5 \\
\hline Market & 15 & 15.5 \\
\hline Friends/relatives & 22 & 22.6 \\
\hline Free house-to-house distribution & 30 & 30.9 \\
\hline Pharmacy & 15 & 15.5 \\
\hline Were ITNs readily available for you & & \\
\hline Yes & 61 & 62.9 \\
\hline No & 36 & 37.1 \\
\hline
\end{tabular}

*Responses from only participants who possessed at least one net.

Table 4. Utilization of ITNs by pregnant women, Nigeria $(\mathbf{N}=97)$

\begin{tabular}{|l|r|r|}
\hline Items & $\boldsymbol{n}$ & $\%$ \\
\hline When did you start using ITNs & 67 & 69.1 \\
\hline Before pregnancy & 16 & 16.5 \\
\hline During 1st trimester & 7 & 7.2 \\
\hline During 2nd trimester & 7 & 7.2 \\
\hline During 3rd trimester & \multicolumn{3}{|c}{} \\
\hline Frequency of use & 68 & 70.0 \\
\hline Always & 9 & 9.3 \\
\hline $\begin{array}{l}\text { Often } \\
\text { Sometimes }\end{array}$ & 20.7 \\
\hline How did you place your ITN & 17 & 17.5 \\
\hline $\begin{array}{l}\text { Hanging it over the windows and doors to prevent } \\
\text { mosquitoes entering the room }\end{array}$ & - & - \\
\hline Hanging it at one corner of the room & 13 & 13.4 \\
\hline $\begin{array}{l}\text { Hanging it over the bed, but the net has contact } \\
\text { with the skin while sleeping under it }\end{array}$ & \\
\hline
\end{tabular}


Table 4. Continued

\begin{tabular}{|c|c|c|}
\hline Items & $n$ & $\%$ \\
\hline $\begin{array}{l}\text { Hanging it over the bed and sleeping under it after } \\
\text { tucking it under the mattress, preventing contact } \\
\text { with the body }\end{array}$ & 67 & 69.1 \\
\hline \multicolumn{3}{|l|}{ Constraining factors to correct usage of an ITN* } \\
\hline It is too costly, I cannot afford it & 6 & 13.9 \\
\hline It causes excessive heat and discomfort & 32 & 74.4 \\
\hline I don't know how to hang it & 39 & 90.7 \\
\hline There is no facility to hang it in my room & 39 & 90.7 \\
\hline I can't use it when the weather is hot & 19 & 44.2 \\
\hline $\begin{array}{l}\text { The routine of raising it every morning after use is } \\
\text { discouraging }\end{array}$ & 13 & 30.2 \\
\hline $\begin{array}{l}\text { I heard that ITNs have a negative effect on the baby } \\
\text { in the womb }\end{array}$ & 41 & 95.3 \\
\hline I did not get it when it was freely distributed & 38 & 88.4 \\
\hline It traps mosquitoes inside when tucked in & 4 & 9.3 \\
\hline \multicolumn{3}{|l|}{ Enhancing factors to correct the use of ITNs* } \\
\hline $\begin{array}{l}\text { Adequate information on how to hang ITNs should } \\
\text { be provided }\end{array}$ & 39 & 90.7 \\
\hline They should be made readily available & 39 & 90.7 \\
\hline They should be given free-of-charge & 42 & 97.7 \\
\hline The price should be reduced & 26 & 60.5 \\
\hline
\end{tabular}

*Responses on constraining and enhancing factors are mutually exclusive.

\section{DISCUSSION}

Knowledge of ITNs for prevention of malaria in pregnancy The findings revealed that the majority of the respondents knew about ITNS and their importance in the prevention of malaria in pregnancy (MIP). This response is not surprising due to the high ongoing public awareness campaign on ITNs. Awareness is also created by the community health extension workers on the importance of ITNs. Even in most primary healthcare centres, the government has provided these nets to be distributed free-of-charge to pregnant women. Their source of information revealed that many became familiar with the ITNs through antenatal care centres. Only a few heard about them from friends and family members. In order to achieve greater awareness, there is a need to expand public knowledge on the importance of ITNs through targeted and multimedia approaches. This is in contrast to the study of Olayemi et al. ${ }^{16}$ which revealed that the majority obtained information about ITNs from friends and newspapers, while none had any health education in the clinic.

Responses to further questions regarding the importance of ITNs during pregnancy revealed that the majority knew that ITNs reduce the contact of the pregnant woman with mosquitoes. These responses indicate that knowledge about ITNs is very high. This is also not surprising because, from the demographic profile, the majority attained a secondary or tertiary education level. The high literacy level, no doubt, played a significant role in their knowledge. Being educated, they are able to comprehend information provided by the newspapers and other mass media. This emphasises the need for measures to improve the educational level/status of women, especially when they are still girls. This result is different to that of Musa et al. ${ }^{17}$ which showed that only one-third of the respondents were aware of ITNs in malaria prevention, indicating that the knowledge was low.

\section{Accessibility of ITNs to pregnant women}

Findings revealed that the majority of the respondents own ITNs. This is in contrast to the findings of Ugwu et al. ${ }^{18}$ on the utilisation of ITNs among pregnant women in Enugu, South-Eastern Nigeria, which showed that only a few of the respondents (43.1\%) owned ITNs. This shows that over the years, there has been a remarkable improvement in the accessibility of ITNs to pregnant women.

Findings also revealed that among the respondents that owned ITNs, the majority got their own during the free houseto-house distribution by the government. Others obtained them from public healthcare centres, pharmacy shops, markets, and friends. Further analysis also reveals that the ITNs were also readily available so that people could purchase them. There have been increased efforts by the government to make ITNs readily available and accessible to pregnant women; the primary healthcare facilities especially are provided with an adequate supply of ITNs that are freely distributed. This makes it easy for this vulnerable group, irrespective of social class, to own at least one ITN. This is however in contrast to the finding of Olayemi et $\mathrm{al}^{16}$ which showed that $62.2 \%$ indicated that ITNs were not readily accessible. There is a need for the government to ensure the safe provision and free distribution of the ITNs. Because of the large size of the ITN market there has also been private production and sale of these nets at affordable prices, which has supplemented the government's efforts to supply the families that missed out on the free nets from the government.

\section{The utilisation of ITNs by pregnant women}

The findings revealed that out of the 97 women that own at least one ITN, the majority started using them even prior to current pregnancy, and $70 \%$ claimed to use an ITN always. Further responses also revealed that most of the women used the ITNs correctly by hanging them over their beds and preventing contact with the body while sleeping underneath. This finding goes a long way to reveal that the efforts made towards creating awareness regarding ITNs have been successful so far. Most people are now sensitised and aware of their own responsibilities to properly use the ITNs in order to benefit from them.

The major constraint to the use of ITNs was a belief that they may have a negative effect on the woman and the unborn baby, despite the high knowledge of ITNs effectiveness for prevention of MIP. Though there is high knowledge/awareness about ITNs, some people have not adequate knowledge to remove misconceptions surrounding ITNs to enable them to accept and use ITNs, especially those whose sources of information are friends and colleagues, instead of the health centres where reliable information is available. This assertion is supported by the low percentage of respondents that indicated that they had been adequately made aware. This is contrast to the findings of Olayemi et al. ${ }^{16}$ where only a 
minority believed that the treated net may have negative and adverse effects on them and their baby. Other reasons were: difficulty in hanging it properly over the bed, and excessive heat and discomfort caused by sleeping under ITNs. Better instructions on how to properly hang ITNs should be given to ensure correct usage. It is also suggested that the ITNs should be distributed free-of-charge or subsidised.

\section{Limitations}

The limitation of the current study is the small sample size. The study included 140 participants selected at convenience and this might limit its generalizability.

\section{CONGLUSIONS}

All pregnant women were ready to use ITNs if adequate information was provided and the nets made readily available at an affordable price or provided free-of-charge; thus, the government is encouraged to continue the provision of ITNs to attain a broader coverage. Health workers at all levels, especially primary level, are also encouraged to increase awareness of the correct usage of ITNs to ensure their full benefit.

\section{REFERENGES}

1. Eckhoff PA. A malaria transmission-directed model of mosquito life cycle and ecology. Malar J. 2011;10:303. doi:10.1186/1475-2875-10-303

2. Isah AY, Nwobodo El. Awareness and utilization of insecticide treated mosquito nets among pregnant mothers at a tertiary health institution in northwestern Nigeria. Niger J Med. 2009;18(2):175-178. doi:10.4314/njm.v18i2.45059

3. Centers for Disease Control and Prevention. World Malaria Report 2009. https://www.cdc.gov/malaria/ features/world_malaria_report_2009.html. Published February 8, 2010. Accessed July 2, 2020.

4. World Health Organization. World Malaria Report 2010. https://www.who.int/malaria/world_malaria_ report_2010/worldmalariareport2010.pdf?ua=1. Published 2010. Accessed July 2, 2020.

5. Onyeneho NG. Sleeping under Insecticide-treated Nets to Prevent Malaria in Nigeria: What Do We Know?. J Health Popul Nutr. 2013;31(2):243-251. doi:10.3329/jhpn.v31i2.16389

6. World Health Organization. World Malaria Report 2009. https://apps.who.int/iris/bitstream/ handle/10665/44234/9789241563901_eng.pdf? sequence=1. Published 2009. Accessed July 2, 2020.

7. World Health Organization. World Malaria Report 2008. https://apps.who.int/iris/bitstream/handle/10665 /43939/9789241563697_eng.pdf? sequence $=1$. Published 2008. Accessed July 2, 2020.

8. World Health Organization. Malaria. https://www.who. int/ith/diseases/malaria/en/. Accessed July 2, 2020.

9. U.S. Department of Health \& Human Services. Malaria, Frequently Asked Questions (FAQs). https://www.cdc. gov/malaria/about/faqs.html. Revised September 17, 2020. Accessed July 2, 2020.

10. Kuti O, Owolabi AT, Makinde ON. Perception of malaria and utilisation of malaria prophylaxis among pregnant Nigerian women at booking. Trop J Obstet Gynaecol. 2006;23(2):125-128. https://www.ajol.info/index.php/ tjog/article/view/84923/74907. Accessed July 2, 2020.

11. World Health Organization. World Malaria Report 2016. https://apps.who.int/iris/bitstream/hand le/10665/252038/9789241511711-eng.pdf? sequence=1. Published 2016. Accessed July 2, 2020.

12. Schantz-Dunn J, Nour NM. Malaria and Pregnancy: A Global Health Perspective. Rev Obstet Gynecol. 2009;2(3):186-192. PMID:19826576.

13. Modebe IA, Nnebue CC, Ibeh NO. Awareness, accessibility and use of insecticide treated nets: a cross-sectional survey of ante-natal clinic attendees in a tertiary hospital in South-East Nigeria. Orient Journal of Medicine. 2013;25(3-4). https://www.ajol. info/index.php/ojm/article/view/94505. Published September 20, 2013. Accessed July 2, 2020.

14. Ter Kuile FO, Terlouw DJ, Phillips-Howard PA, et al. Reduction of malaria during pregnancy by permethrintreated bed nets in an area of intense perennial malaria transmission in western Kenya. Am J Trop Med Hyg. 2003;68(Suppl 4):50-60. doi:10.4269/ajtmh.2003.68.50

15. Nigeria Federal Ministry of Health, National Malaria Elimination Programme. Malaria ACSM Guidelines: Strategic Framework and Implementation Guidelines for Advocacy, Communication and Social Mobilisation Programmes, 2014. http://gbchealth.org/wpcontent/uploads/2015/05/Nigeria-Malaria-ACSM.pdf. Accessed July 2, 2020.

16. Olayemi SO, Oreagba IA, Mabadeje AF. Knowledge and practice of the use of insecticide treated nets among mothers in Lagos, Nigeria (A Preliminary Survey). Nig Q J Hosp Med. 2004;14(2). doi:10.4314/nqjhm.v14i2.12717

17. Musa OI, Salaudeen GA, Jimoh RO. Awareness and use of insecticide treated nets among women attending ante-natal clinic in a northern state of Nigeria. J Pak Med Assoc. 2009;59(6):354-358. PMID:19534367.

18. Ugwu EO, Ezechukwu PC, Obi SN, Ugwu AO, Okeke TC. Utilization of insecticide treated nets among pregnant women in Enugu, South Eastern Nigeria. Niger J Clin Pract. 2013;16(3):292-296. doi:10.4103/1119-3077.113449

\section{ACKNOWLEDGMENTS}

We thank our research assistants and the study participants for their time.

\section{CONFLICTS OF INTEREST}

The authors have completed and submitted the ICMJE Form for Disclosure of Potential Conflicts of Interest and none was reported.

\section{FUNDING}

There was no source of funding for this research.

\section{PROVENANCE AND PEER REVIEW}

Not commissioned; externally peer reviewed. 